\title{
Editoríal.
}

\section{MENTAL DISSOCIATION.}

$T^{T}$ is not always sufficiently realized that dissociation or disjunction is, like association, an essential function of the normal mind. As, in the course of life, the individual consciously adapts himself to his environment and gains stability and personality by the organisation of his interests, he has not only to accept but to reject, and this rejection involves dissociation, just as acceptance involves association. As regards dissociation in pathological cases, the writers of the last generation thought of this in terms of associationist psychology, and in the doctrine of Pierre Janet one finds that standpoint still apparent. In his description of cases of hysteria and multiple personality he implies a general background of explanation, according to which personality may be regarded as a synthesis of mental presentations some of which can be split off from the main mass. This view is similar to the 'colonial' view of personality which we find in the writings of Ribot. But if we remind ourselves of the fact that experience involves an act of experiencing we see that the situation is rather different. The power of recall is an essential aspect of conscious memory. On the other hand, unconscious memories are unconscious or latent mental activities directed towards past events. They are not passive, but involve a certain amount of mental energy. And so we pass from Pierre Janet's theory to the theory of Freud, and find that the dissociation which is taken as a fact in Janet's theory is explained in Freud's theory in terms of mental conflict and repression. These memories become inaccessible to the individual because the mental tendencies corresponding to them are in conflict with other tendencies of the individual and incompatible with his more fundamental interests. So they are extruded by an active process of repression-they are barred from consciousness. That process of repression and extrusion, though pathological in these cases, need not necessarily be so. We must not look upon extrusion itself as essentially 
pathological. It is because we have restricted the word dissociation so much to the pathological side that we find it so incomprehensible. It is because we have thought too much in terms of mental unity that cases of multiple personality seem to be inexplicable. Actually the most normal mind is a multiplicity. We are all many selves. We have to face the world from many different angles. We have many different interests. Interests in the most normal mind may conflict and be incompatible with one another. And it is a condition of mental health that such conflict can be resolved by elimination or by a higher synthesis. What makes the dissociation of multiple personality pathological, is that the elimination is not complete--that dissociation in normal mental activity is a successful reaction, and that dissociation in a pathological case is unsuccessful-is an incomplete and therefore an unsuccessful reaction. A tendency that is repressed is, as it were, rejected and accepted at the same time-rejected by clear consciousness, but still clung to by the mind.

It is misleading to look upon the problem of mental dissociation and multiple personality as something standing by itself, as if we understood mental unity and were perplexed by the appearance of multiplicity. Multiplicity is an aspect of the normal mind, just as much as unity is, and unity needs explaining just as much as multiplicity does. Those two problems must be solved together and kept in relation to one another all through.

Many of the classical cases of multiple personality are fully explained along these lines. They are cases of alternating personality with reciprocal amnesia, as it is called, in which each personality is unable to recall the experiences of the other. The two individuals $\mathrm{A}$ and $\mathrm{B}$ alternate with one another. A has his own system of memories and, when he disappears and makes way for B, B has his system of memories distinct from the memories of $\mathrm{A}$. We may explain this in terms of two general systems of interests which are mutually incompatible and in conflict with one another. As a rule, one part of the personality is more fundamental, i.e., more stable than the other. But difficulty arises in cases where one personality is shut up within its own memories and experiences, while the other personality has access to those memories as well as to its own. A may have his system of memories but be quite ignorant of $B$, except from indirect evidence, whereas $B$ not only has a special set of memories, but also has direct knowledge of A's memories, thoughts and feelings. This is a difficult 
problem which needs to be faced. We find an analogous, though not identical, situation in most cases of deep hypnosis. When a patient passes into the hypnotic state, he may remain fully aware of his waking consciousness, and may have free access to the memories of his waking self. But on awaking he does not, as a rule, remember his hypnotic experiences. The relation is a one-sided one. The hypnotic personality is acquainted with the waking personality, and all its memories, but the waking personality is not acquainted with the hypnotic personality. The range of the hypnotic personality is wider than the range of the waking personality. This similarity between one-sided multiple personality and the hypnotic personality is significant, when we remember that such cases have been investigated by the hypnotic method. Pierre Janet, Morton Prince and others used the hypnotic method in studying cases of multiple personality, and the criticism has been made against them that in doing so they were manufacturing personalitiesthat the personalities were artifacts produced by the method. Everyone recognizes that these investigators are psychologists of exceptional ability and circumspection and honesty of purpose, thoroughly trained and alive to the possibilities and difficulties of their method. We cannot dismiss their observations as false observations, or as misunderstandings on their part. But we must nevertheless allow for the influence of the process of hypnosis in the result, and as contrasted with that earlier period of investigation - the hypnotic period in psychopathology -we find that, now that hypnosis is seldom used and has been replaced by deep analysis, cases of multiple personality are not on record. The psychoanalysts to-day seem to have no such cases to report. Moreover, if we contrast the very large number of cases of severe nervous disturbance caused by the late war with the absence of cases of multiple personality there, we may become still more impressed by the argument that it was the persistent use of the hypnotic method that was mainly responsible for the complexity of most of the earlier cases reported.

The movement of thought is always towards system and unity. Thought abhors hard-and-fast distinctions. Thought is baffled by cases of multiple personality, because they are so different from the ordinary cases of everyday life. If we can build a bridge between one group of cases and the other, then we may feel that we are likely to have not only a more satisfying but a truer explanation of the situation. 
We must therefore approach the question of dissociation from the normal side-as manifested in a relatively normal mind. No mind is completely normal, since no mind completely solves its problems from day to day, and it is the failure to solve mental problems which is one of the general causes of the symptoms of psychoneurosis and mental disease. Dissociation and multiple personality are not to be contrasted with association and mental unity. Pathological dissociation should be contrasted with the dissociationist processes of the normal mind. It should be regarded as a failure of the normal process of dissociation.

The unity of the normal mind, although it is there from the beginning, is a striving towards a more and more complete association ; it constitutes an 'urge' to a greater and greater degree of completeness of systematization and inclusiveness, but it is never really complete. In the most normal mind there is a falling away from complete unity. There is in the activity of this unitary mind not only a normal process of disjunction or dissociation, but also a certain degree of abnormal dissociation. In cases of multiple personality this abnormal dissociation has become so pronounced as to become apparent to the whole world. The process of deep analysis or psychoanalysis fails to reveal cases of thorough-going multiplicity, and the reason is that the process itself is a process of unification. As the individual is being analysed, the failures of adaptation in his past life are cleared up, and so his mind is enabled to work more and more normally. Analysis is not a good term for this process. It is more than analysis, it is a process of self-revelation or autognosis. The individual learns to know himself better, and in the process of analysis there is actual development of the mind going on. There is a development in the direction of the normal and the unitary. Any dissociation that is encouraged by the method is a normal dissociation, not an abnormal dissociation. It is only another expression of the same truth when we say that repressions are overcome in the process of analysis, because repressions are pathological dissociationsdissociations that are not complete and not thorough-going.

In contrast with this process of autognosis, the process of hypnotic investigation carries with it a tendency to dissociation. A person who is easily hypnotised is a person who is already, to some extent, dissociated; in hypnotising him we take a wedge, as it were, and drive it into his mind and split him up still more. No wonder the results give us an appearance of dissociation; but it would be very dangerous for us to take 
these results at their face value and draw inferences from them as to the structure of the normal mind, or even of the mind of the person we have been experimenting with. What may happen when we do take these phenomena at their face value is illustrated in such a theory as that of Professor W. McDougall in the last chapter of his "Outline of Abnormal Psychology," in which he works out a theory of the Self as a system of monads which form a hierarchy, in which there is one dominant monad, the conscious self and a whole number of subsidiary monads that are in a normal mind adequately subordinated to the chief monad and are in relation to the chief monad through telepathy*; but in a case of multiple personality one of these subsidiary monads may break loose and become insubordinate. This is an ingenious theory, and it may be true, but in the present state of our knowledge it would seem to be a case of explaining obscurum per obscurius. Telepathy may be a fact, but it is something about whose conditions we know nothing, and to appeal to it as a fundamental factor in an explanation of $\mathrm{h}$ ? working of the mind seems to be a doubtful procedure.

* Cnlike the monads of Leibniz, which "have no windows," and are in a relation of preestablished harmony. 